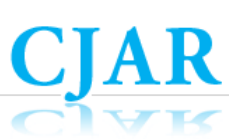

Canadian Journal of Action Research Volume 19, Issue 2, 2018, pages 26-47

\title{
COLLABORATIVE ACTION RESEARCH TO IMPLEMENT SOCIAL- EMOTIONAL LEARNING IN A RURAL ELEMENTARY SCHOOL: HELPING STUDENTS BECOME “LITTLE KIDS WITH BIG WORDS”
}

Donna M. San Antonio

Lesley University, Cambridge, MA

\begin{abstract}
Research has shown that social and emotional learning (SEL) can benefit students in affective, interpersonal, communicative, and academic realms. However, teachers integrating SEL face a variety of logistical, pedagogical, and skill development challenges, including how to effectively facilitate classroom conversations on social justice and personal loss. This article draws from classroom observations, teacher conversations, interactive journals, and field notes to describe a seven-month-long university-school partnership to carry out an action research project in a high-poverty rural elementary school in the US. Teachers grappled with how to address race, immigration, and gender discrimination in a predominantly White community. Classroom vignettes, and teacher and author reflections, illustrate the iterative, developmental, and reciprocal aspects of learning between teachers and students, and between the university-based facilitator and teachers.
\end{abstract}

KEYWORDS: Action research, social-emotional learning, curriculum implementation, teaching elementary school, collaborative consultation, rural schools, cross-cultural awareness

\section{INTRODUCTION}

Toward the end of the school year, I sat in Catherine's sixth grade classroom one last time. Students were discussing the book, Bud, Not Buddy (Curtis, 2002), a story about an African American boy from Flint, Michigan who goes on the road in search of his father in 1936. 
This classroom session is part of the Voices curriculum-social and emotional learning designed to be integrated into language arts lessons. Longing for connection with an absent parent resonated with students and they could not wait to hear what would happen when Buddy finally met his dad.

Classroom conversations are a core pedagogical tool for this curriculum. At the beginning of the school year, when teachers were first introduced to the new curriculum, they worried that their students would not relate to the characters in the books who were from diverse backgrounds and urban settings. And they worried about their own skill: How would they facilitate the difficult, emotionally charged classroom conversations that the curriculum encouraged? But, when Catherine asked her students, "What things get in the way of something you want to do?" they quickly leaned into this question, sharing stories about struggle and loss: sick family members, not having enough money, being injured, a parent that left them, and pets that died. While there was only one student of color in this class of 19 white students, these eleven-year-olds seemed to have no trouble identifying with Buddy.

When teachers integrate SEL they face a variety of logistical, pedagogical, and emotional challenges, including how to effectively facilitate classroom conversations on social justice and personal loss. This article describes a university-school partnership to carry out a collaborative action research project with seven rural elementary school educators, in the first year of teaching a highly interactive, language-rich, multi-cultural SEL curriculum. I draw from classroom observations, teacher conversations, interactive journals, field notes, and my reflective notes to describe the structure, purposes, and outcomes of this project implemented in a high-poverty rural elementary school in northeastern United States. This study addresses the key concerns of teachers during the curriculum implementation process; the way these concerns were engaged through action research by the facilitator (the author); and the new understanding, skills, ethics, and ways of being that were learned and enacted.

Consistent with action research's call to prioritize context-specific efforts (BradburyHuang, 2010) I begin with a brief portrait of the school and community. Following a discussion of social emotional learning, action research, and collaborative facilitation, I report findings using classroom vignettes and teacher reflections to illustrate change over time-the iterative, developmental, and reciprocal aspects of learning between teachers and students, and among action research collaborators.

\section{Community AND School ConTeXt}

The town of Hillside ${ }^{1}$ is nestled between forested rolling hills in a rural landscape of small villages, farmland, and lakes. It is located in northeastern United States, a 3.5-hour drive to the Canadian border, and has a population of about 4,300 people, $98 \%$ of whom are

${ }^{1}$ The names of all people and places have been changed to protect confidentiality. 
Caucasian. The town is in a geographically expansive, seven-town school district that has six elementary schools and a regional middle and high school. As a whole, residents of Hillside fall well below the state average for income, employment, and educational attainment, and above the state average for poverty, disability, and homelessness, according to the most recent town profile by the state Office of Employment Security. Like many rural elementary schools, Hillside Central School is the heart of the community-a place that strengthens community identity and reinforces a positive sense of community (Tieken, 2014). At the end of every school day, dozens of parents arrive before release time to visit with each other and with teachers while they wait for their children.

When the project began, Hillside Central School had not met its benchmark for Adequate Yearly Progress (AYP) for three years and, as mandated by the No Child Left Behind Act of 2001,2 it was designated as a school "in need of improvement," and subject to changes required by the state. But, in the Hillside community, local relationships matter and state mandates are viewed with suspicion. There was a strong sense that "we can make things better here on our own." When, under the law, parents were offered the option of transferring their children to a different school, the response was a resounding, "No. Our children aren't going anywhere." One of several strategies educators adopted to improve test scores was the implementation of a new core curriculum for Language Arts that integrated social-emotional learning.

\section{Teachers' Objectives for the New Curriculum}

Hillside Central School students were among the poorest students in the school district and they had long been the target of social class bias-an issue that was particularly salient for students and parents during the transition from elementary school to the economically diverse regional middle school (San Antonio, 2004). Along with improving reading and communication skills, Hillside educators had five other intentions for the new curriculum: prepare students to be ready academically, socially, and emotionally for the transitions ahead; increase participatory inclusion of all students; reduce incidents of teasing and bullying; expand students' awareness of social issues; and foster well-being by safely bringing the emotional lives of students into the classroom. The new curriculum used carefully selected texts that had young protagonists from all race, culture, and class backgrounds, facing interpersonal and moral dilemmas, such as those posed by prejudice, disability, separation from a family member, and friendship struggles. For most teachers, bringing these themes into the classroom required new skills, attitudes, pedagogies, and ways of thinking.

\section{SOCIAL AND EMOTIONAL LEARNING}

Increasingly, there is emphasis on the development of empathy, affiliation, and civic responsibility as a primary concern of schooling, particularly when race, ethnicity, gender, physical ability, and sexual orientation place students at risk socially, emotionally, and/or academically (Hoffman, 2009). Research links social-emotional learning (SEL) with

\footnotetext{
2 The state request to waive NCLB sanctions was approved in 2013; however, educators at Hillside Central
} School continued to set ambitious benchmarks for academic improvement. 
improved school climate, increased awareness of self and others, openness to diversity, and sense of civic responsibility (Durlak, Weissberg, Dymnicki, Taylor, \& Schellinger, 2011; Smith \& Low, 2013), and these benefits can promote positive academic outcomes (Zins, Weissberg, Wang, \& Walberg, 2004).

\section{Social Learning and Identity Development}

The chosen curriculum required teachers to facilitate highly participatory classroom conversations in which students formulate and articulate their points of view on complex interpersonal, affective, and societal issues. This aspect of SEL is grounded in social learning theory (Bandura, 1977) and acknowledges peer interactions as a fundamental, but often under-utilized, aspect of classroom learning. Peer-to-peer conversations in the SEL classroom are geared toward communicative competence in which students learn to be engaged as both speakers and listeners, attentive to their own experience and to the experience of others and exercising their ability to use words to express complex thoughts and feelings (Elizabeth, Ross, Snow, \& Selman, 2012). Language-rich SEL curricula like the one implemented in Hillside are designed to promote self-awareness, perspective-taking ability, interpersonal communication skills, cultural awareness, and civic responsibility.

\section{Implementing SEL Curricula}

Elias (2006) wrote that SEL,

...represents a part of education that links academic knowledge with a specific set of skills important to success in schools, families, communities, workplaces, and life in general. As national and world events continue to teach, there is a danger to each of us-locally and globally-when children grow up with knowledge but without social-emotional skills and a strong moral compass. Hence, a combination of academic learning and SEL is the true standard for effective education for the world as we now face it (p. 6).

To address these concerns and aims, Elias recommended fully integrating SEL into the curriculum; involving parents; preparing and supporting teachers; and evaluating results. There has been significant progress in the implementation and practice of social-emotional learning within subject areas, such as social studies (Nucci, Creane, \& Powers, 2015) and language arts (Collaborative for Academic and Social-Emotional Learning, https://casel.org/what-is-sel/approaches/). However, implementation of SEL poses many challenges and schools struggle with how to integrate SEL into a school day that is already brimming with curricula and assessment demands (Kress \& Elias, 2006). When Meyers, Tobin, Huber, Conway, and Shelvin, 2015) conducted a regional study on SEL implementation in low-income rural schools, they documented the struggles and successes, and they recommended inter-disciplinary, cross-role collaboration, involving administrators, school counselors, teachers, and parents.

In their large-scale meta-analysis, Durlak et al. (2011) concluded, "Developing an evidencebased intervention is an essential but insufficient condition for success" (p. 218). The curriculum must also be well-implemented and well-taught. To change classroom practice 
in a meaningful way, schools must be willing to "realign structures and relationships to achieve genuine and sustainable change" (Elias, O'Brien, \& Weissberg, 2006, p. 11). This is especially true when implementing a curriculum that requires new technical, pedagogical, and classroom management skills, and this challenge may be even more daunting in underresourced rural areas (Kreuger, 2005). There is a need for focused and sustained support for professional development that fosters inspiration and solidarity among teachers, and that is a collaborative, reflective, dialogic, long-term process, and relevant to the particular context (Cochran-Smith and Lytle, 2001; Johnson, 2001; Villegas-Reimers, 2003).

\section{Professional Learning Communities}

Multi-year studies that explore the use of professional learning communities as a vehicle for change in classroom practice are rare, but Grierson and Woloshyn (2005) provide a useful example in their two-year-long study of an elementary school action research learning community. Clausen, Aquino, and Wideman (2009) conducted research in a school similar to the one described in this article. They found that, although collaborative learning efforts are desirable and have beneficial outcomes for schools, effective learning communities are hard to initiate and even more difficult to sustain. Using school-based examples, these authors cautioned, "...the characteristics found in any of these fragile, newborn communities will probably not measure up to the 'ideal' set by the literature" ( $p$. 451). Indeed, these words echo through my findings when considering aspects of professional learning that grew deep roots and were sustainable, and aspects that did not hold up over time.

\section{ACTION RESEARCH}

Social-emotional learning and action research exercise similar skills and have some common purposes. The implementation project described in this article combined a variety of methods and pivoted around collaborative action research as a core strategy.

\section{“Contact Zone"}

School-based action research-ideally a dialogic process-is an iterative method in which classroom practice leads to critical refection, articulation of salient questions, collection and analysis of data, identification of adjustments that can be implemented in practice, testing new practices, and then circling back to reflection, asking new questions, and so forth (Brighton, 2009; Lewin, 1947; Sagor, 2000). Several authors have written about action research as an effective method to support successful implementation of socialemotional learning curricula in marginalized communities (for example, see Balakrishnan \& Claiborne, 2012; Cohen, 2006; Ng-A-Fook, Radford, Yazdanian, \& Norris, 2013).

In her most recent book, Michelle Fine (2018) is unequivocal about the importance of school-based critical participatory action research as a tool for individual and collective liberation and social change. Using youth action research projects as examples she shows how young people, especially those in precarious economic and social situation, are eager to discuss injustice, and to learn about how to respond to it. When the stakes are high among differently situated people, action research creates a messy social space where people "...meet, clash, and grapple with each other, across varying relationships to power" 
(Cammorota \& Fine, 2008, p. 25). Hillside students, many of them living with economic insecurity and family instability, were afforded the opportunity to learn about social justice movements and put words to their own experiences. Consequently, teachers in this project had to grapple with placing themselves in a "contact zone," sometimes teeming with emotion, as some of the examples below will show.

Kemmis (2009) linked fundamental aspects of action research with participatory action research and critical participatory action research and presented action research as a way to "change practitioner's practice, their understanding of practice, and the conditions of their practice" (p. 463). Efforts in action research, then, are aimed toward transforming what participants do, think, and say, and how they relate to each other within the contexts in which they operate. A key challenge for university-based partners is to be transparent about how they define action research and their expectations and hopes, and to seek consensus among all participants concerning these aims. How can a collaborative outsider facilitator optimize the potential benefit of action research?

\section{Collaborative Facilitation in University-School Partnerships}

Teacher dialogue, collective problem-solving, shared leadership, and commitment to improving practice are core qualities of collaborative action research that a university facilitator can help to foster (Conoley \& Conoley, 2010; Friend \& Cook, 2007; Goddard, Goddard, \& Tschannen-Moran, 2007; Peterson et al., 2010). Importantly, the collaborative facilitator holds an epistemological standpoint of "intellectual humility" - a position that is informed by local needs and practice-based knowledge, and open to re-conceptualizing, reassessing, and adjusting direction, pace, role and goals, all along the way, based on inputs from school-based partners (Hill \& Sandage, 2016; Truscott, Kearney, David, \& Roach, 2016).

Action research partnerships, organized around a core ethic of intellectual humility, are fundamentally grounded in the co-construction of knowledge and egalitarian relationships in decision-making. Instead of a "...university expert dispensing research-based information and knowledge flowing in one direction," there is an open exchange and reciprocal learning (Kroeger, Beirne, \& Kraus, 2015, p. 360). In their case study of a university-school partnership, these authors underscored the pushes and pulls at play in the way a university-based partner enacts his/her role. They described a process that involves accompaniment and intervention, critical reflection and action, experimentation and evaluation.

\section{RESEARCH METHODS \\ Participants}

When Hillside Central, a K-6 elementary school, adopted literacy-based social and emotional learning, all teachers were required to implement the curriculum, but teacher participation in the seven-month long consultation and action research project was voluntary. Seven teachers, grades 3-6, agreed to participate; they were all Caucasian females, from 20-something to 40-something, with teaching experience ranging from three 
to eleven years. Teachers received a small stipend and two graduate credits for their participation.

\section{Research Design}

I am a community counselor and university professor, with a long history of partnering with the school district. As project manager, I was joined by four graduate students who focused their inquiry on the evolution of classroom conversations, while I focused on facilitating and documenting the various components of action research and teachers' perceptions of their skill development. In this article, I discuss only my own first-hand observations, conversations, field notes, and teacher journals sent specifically to me.

School visits were twice-a-month, for seven months, and involved classroom observations of lessons in grades 3-6, followed by post-observation debrief discussions that gave teachers the opportunity to articulate successes, uncertainties, frustrations, and insights. Observed classroom lessons were audio recorded and transcribed, and I took field notes and interpretive-reflective memos on classroom interactions. Debrief sessions involved two or three teachers at a time; these conversations were also audio-recorded and transcribed. Based on content that arose during debrief discussions, I emailed follow-up prompts to the teachers and asked them to engage in reflective journaling and critical analysis of their practice, a strategy described by Nakkula \& Ravitch (1997). After the first year of curriculum implementation, I visited the school each year for four years for follow up conversations with teachers.

\section{Focus and Analysis}

To prepare this article, I read classroom and debrief transcripts, field notes, teacher journals, and my notes from follow-up interviews multiple times, and used an open, qualitative coding scheme to identify key themes that emerged (Boyatzis, 1998). I shared my interpretations with graduate students and with teachers to explore diverging points of view and to inform the analysis presented here. The focus of this study is on these questions: What were the key concerns of teachers during the curriculum implementation process and how were these concerns engaged through action research by the facilitator (the author)? What skills, ethics, and ways of being were learned? How did reflection on practice lead to new understanding, growth, and change?

\section{ACTION RESEARCH Components}

In addition to the components described above, several other components were part of this action research project. At the beginning of the school year, family nights brought educators, parents, and students together to share a meal and discuss the new curriculum. We used experiential activities to spark conversations among families. Using email, I responded to teachers' monthly journal entries (seven in all). This response was a relationship-building strategy and a way to make suggestions, offer a reading or resource, and reinforce teachers' abilities to probe their practice for deeper awareness. In addition, I facilitated monthly professional development sessions to address the questions and dilemmas that were most salient. At the end of the school year, the teachers presented $a$ 
workshop for the school district on what they learned and what had changed in classroom practices and in student interactions.

In the following sections, there are examples from the beginning, middle, and end of the school year that demonstrate teachers' emerging concerns and evolving practices. Findings are organized around six themes: acknowledging emotion and discerning what is at stake, understanding the complex ecology of social and emotional development, modeling compassion and courage, creating a problem-reframing attitude, moving toward principled reasoning and civic responsibility, cultural awareness, and empowering students.

\section{EARLY CONCERNS: FACILITATING DIFFICULT CLASSROOM CONVERSATIONS}

On a crisp, sunny day in late fall, I arrived at school shortly after the day began and joined a lesson that was just starting. Classroom walls displayed a collage of student work and six colorful posters describing the themes of the Voices curriculum: Identity Awareness; Perspective-Taking; Conflict Resolution; Family, Friends, and Community; Social Awareness; and Democracy (Selman, 2003). Two months into the school year, teachers were beginning to have a sense of the possibilities and challenges of using this new curriculum. But teachers also revealed that they were so busy juggling multiple interactions and emotions, they hardly had time to register what was going on internally for them and their students. Collaborative action research provided the opportunity for teachers to pause, take in what they were experiencing, and share their concerns and strategies with each other.

\section{Opening a Space for Emotion: What is at Stake?}

A worry that emerged most persistently, and with the highest level of relevance to all teachers early in the school year, was described by third grade teacher, Kathy: "One of the most difficult pieces for me as a teacher has been the sensitive topics. At times, I felt uneasy and unsure what was okay to discuss and what was not okay." The new curriculum introduced multicultural themes and teachers thought their students would, "...have a hard time understanding perspectives of other people... They are not exposed to life outside of their town...they can't relate or even begin to understand what happens outside of Hillside." The debrief discussion transcripts and teachers' journal entries repeatedly referred to these concerns. Would these rural, mostly White, low-income students be able to identify with the racially diverse children in the texts? They also wondered: How do they as White teachers discuss race in a racially homogeneous town? It became important to help teachers articulate these concerns and facilitate conversations with each other in order to explore which concerns were well-founded and which were a function of implicit bias, uncertainty, lack of confidence, or a sense of emotional precariousness.

With the new curriculum, students discussed their lives more openly, sometimes making private information classroom knowledge. For example, when reading Because of Winn Dixie (DiCamillo, 2009) early in the school year, one third-grade student identified with the book's protagonist and quietly told her teacher and classmates, "My mother left me too." Teachers had to face the burdens and emotions experienced by their students more than ever before, and they shared their anxiety and their sadness upon entering this emotional 
territory. They sometimes feared they could do harm: "I am not a counselor. I am not trained to do this," stated one teacher and this was felt by others. However, they found that their students easily and quickly walked into these tender places, eager to share a painful death, recent divorce, or serious illness of a family member. Creating a mutually respectful space for skill development, and a "holding space" for teacher concerns like these, became imperative for me.

\section{The Complex Ecology of Social and Emotional Development}

Now that teachers were regularly engaging their students in conversations about race and racism, the language of prejudice came into the classroom and demanded an effective response from teachers. In this small rural community, where teachers and parents regularly interacted with each other in and out of school, teachers were sensitive to how parents might respond to what they were saying or doing in the classroom, and they were mindful of how their words could be misconstrued. For example, when a fourth-grade teacher discussed gender roles and used the phrase "sexual discrimination" in class, a student called out, "I'm going to go home and tell my mom you said 'sex' in class!"

At first, teachers focused on the students' lack of exposure to diversity as a key factor in making the implementation of this curriculum difficult. Teachers were grappling with roles and boundaries; they were genuinely concerned that their hard-won relationships with parents might be compromised if they were not cautious. For example, in response to the journal prompt, Please describe a recent experience facilitating a conversation about a topic that is hard to discuss in the classroom, a third-grade teacher wrote about a classroom discussion about racism:

...A student in my class shared that her father and friends often used the word "n__" in their house. Many of my other students asked what that word meant. My mind went blank! I wanted to tell my students that they were not allowed and will not speak like that, but I also knew that it wasn't right to teach a child that their parent was wrong... I took a minute and I explained that often people use slang words for people based on what they see on the outside. Many kids brought up that they might make fun of someone or call them a name just because they are unaware of what to expect. I had students decide in our conversation if it was right or wrong. I was waiting for the phone to ring, thinking an angry parent would want to know why I was telling their child about how they should respond to prejudice and slang words being used in their homes.

Teachers often brought up concerns that this social justice-oriented curriculum could be at odds with the values and beliefs of the community and that their relationships with parents might be compromised. By bringing these fears and concerns into dialogue with other teachers, collaborative action research can use collective problem-solving and problemreframing to support teachers through a learning process that feels risky at times. The teacher in the above example did exactly what the curriculum asks teachers to do: she effectively facilitated a discussion so that students would hear different points of view, and 
she made the discussion personally relevant to her students. This classroom experience gave us the opportunity to demonstrate how to transform an uncomfortable conversation into a conversation about prejudice that was grounded in the lived experience of students.

Those angry parent phone calls never came. But what if they had? This teachers' frank reflection helped me to understand that it is important to discern what is at the root of teachers' worries. Is the concern coming from a lack of confidence in responding to a parent? Is it based in a societal bias that working class, rural white parents are intolerant of different points of view; uneasiness about addressing racial themes in the classroom; a combination of these or something else? Clarifying underlying concerns, understanding the flashpoint of these concerns, and engaging in dialogue with others, helped teachers to speak more honestly about their own vulnerabilities, biases, and misgivings.

However, this example also points to a missed opportunity to facilitate a deeper conversation about how comparing derogatory racial slurs to other types of interpersonal insults minimizes the history and harm of racism. The lesson described above could have been a useful springboard for a discussion about how to facilitate classroom conversations about racial prejudice and injustice, the use of racist language to subjugate others, and the activism of youth and adults to confront these issues. ${ }^{3}$

In reflecting on my own missed opportunities, I realized how much I was operating on an assumption that bringing these critical questions to teachers for discussion, could compromise another important objective: to build and sustain strong, respectful, collaborative relationships. A university-based facilitator of action research can sometimes be a precarious position, simultaneously straddling a collaborative facilitation stance and the responsibility to name bias and injustice and scaffold the development of classroom skills that foster awareness.

\section{Mid-year: Going Deeper and Teachers' Desire to Know Their Students}

Early in the school year, teachers tried to avoid difficult conversations but mid-way through the year, they walked more confidently with their students into unknown social and emotional territory. They began to learn how to manage the detours that can happen when the issues of individual students became all-encompassing in the classroom. As the project progressed, teachers carefully used autobiographical information to encourage students to speak about their own experience. Questions and concerns shifted from, "My students have limitations" to "How can I facilitate learning at a deeper level?"

\section{Modeling Compassion and Courage}

Responding to the journal prompt: What are the identities, concerns, resources, values, scarcities, and possible losses and longings that impact your students? teachers wrote sensitively about the stressors in their students' lives, including poverty, incarcerated parents, domestic violence, neglect, and maltreatment. Sixth grade teacher, Catherine,

\footnotetext{
${ }^{3}$ A useful resource to assist these conversations is Shakil Choudhury's 2015 book, Deep diversity: Overcoming us vs. them.
} 
wrote, "Knowing my students is critical to understanding where to go with these classroom conversations." While she worried that raising sensitive topics might trigger embarrassment or shame, she also asserted that it is "...less lonely [for students] to know that others share similar plights." Teachers began to feel a strong desire to connect with alienated and lonely students so that these students might feel seen and heard in the classroom.

In response to the journal question: How do you make decisions regarding classroom discussions on personal and emotional subjects? Catherine wrote about how she can sense when students are emotionally connecting to the material:

While reading Charlie Pippin (Boyd, 2011), I was worried the students wouldn't be able to make a connection with the Vietnam War. However, as I read the story, I noticed some of my students were really paying attention...all of a sudden, I can just "feel" around me that the words in the story have struck a nerve. I asked the question, "Do you know anyone who has ever been in a war?" I often will model a response by giving my own connection...I told the class about my brother.

Thorny as it was at times, there was a sense of shared commitment among teachers to open a door for the lived experiences of students and to carefully share their own stories when relevant. At this juncture, my role was to be a witness to teachers' difficult classroom work in order to enable them to view their own work with less self-judgement and with more understanding and appreciation. When we were successful in cultivating a compassionate listening environment, students felt seen and heard by their teachers and peers and they more readily expressed compassion toward others.

\section{Creating a Problem-Reframing Attitude}

As the practical issues were addressed, and as students demonstrated their eagerness to engage in reading and discussing new texts, teachers' concerns began to focus squarely on pedagogy and re-conceptualizing their classroom role. They now asked questions about their own edge of development, and they worked together to delve into dilemmas, reframe them, and try new things. For example, one teacher posed this dilemma: "The classroom conversations are great but can easily go too far from the reading and the goals of the lesson. I'm not sure when and how to reel it in or re-direct." Another teacher asked, "How does a teacher judge how far to go when a student is relaying personal stories?"

These concerns persisted throughout the year; however, teachers also spoke about the changes they were experiencing. In an April journal entry, fourth grade teacher, Elizabeth, expressed an interpretational shift and a level of comfort that was also voiced by her colleagues:

At first, I just felt overwhelmed by the whole program. I felt introducing the intense storylines and complicated vocabulary would be horrible and too time consuming. I edged slowly into this program with apprehension... What strikes 
me about my students is that their determination is amazing, considering what they are experiencing. I take that as inspiration to push them further, even when they struggle.

This is significant in a school that had been plagued by low academic expectations and social class biases. Teachers and students alike reveled in the progress they made and the hard-won skills and successes they had. Turner (1982) pointed out that once practical concerns are addressed in curriculum implementation, efforts often stop short of higher level personal and pedagogical insight. By sustaining a collaborative effort, we established a reciprocal learning environment that was effective for the developmental growth of students, teachers, and for me as the facilitator of this project.

\section{Moving Toward Principled Reasoning and Civic Responsibility}

By spring, teachers spoke about their delight when they were able to facilitate tender and meaningful classroom discussions and when they saw students making tangible advances in social development. One such classroom conversation serves as a good example of how to stretch students' thinking toward a more complex understanding of racial injustice. Mallory's third graders were discussing Uncle Jeb's Barbershop (Mitchell, 1998), a picture book about the only Black barber in a southern town in the 1920's. The segment below is from the transcription of the students' conversation:

Meredith: I think White people should cut White people and Black people should cut Black people's hair.

Teacher: Do you think so? Do you think they were right to have separate barbershops?

Jacob: No.

Meredith: Yes.

Here, the teacher has to decide whether to direct a question to Jacob or Meredith, as well as whether or not to raise a moral argument against segregation. She lets the conversation unfold, trusting her students to be teachers. Instead of pulling the conversation in the "right" direction, she decides to ask Meredith about her point of view. Over and over again, I saw young students stretch toward new understandings of the world when their words were taken seriously and when they had a chance to engage in well-facilitated dialogue with their peers.

Teacher: So why do you think they should have?

Meredith: Because the Whites were being really mean to the Black people. And I think they should be treated fairly, the same way.

Teacher: Okay. So, Meredith thinks that it is a good thing because the White people were being mean to the Black people. That way the Black people didn't have to be around people who were being mean to them. Is that what you are saying? So, you think it's [segregation] a good thing?

Celeste: No.

Teacher: Do you think there was a different way to solve the problem? 
Jacob: I disagree with Meredith.

Teacher: You do? Tell us why.

Jacob: I think it would be better if there weren't separate barbers. There's one Black barber and the rest are all White barbers. It's not fair; the colored can't get as many haircuts...

Teacher: This wasn't a problem that they could solve on their own, was it? If you remember, when we talked about Martin Luther King, Jr.? Remember how he tried to help everybody and it took a long, long time to end segregation? Remember how we talked about Ruby Bridges?

Devany: She went to the White school and all the White people were mad.

Mallory then builds on this foundation to move her students toward Kohlberg's (1976, 1981) "principled conscience" by asking if and how they have confronted injustice in their own lives. She guides her nine-year-old students through difficult questions as they discuss race relations, discrimination, and justice. The complexity of the issue is clear as they disagree with each other about what is fair and what is safe for Black people. In a way that recalls Gilligan's (1982) insights on gender differences in moral reasoning, Mercedes takes a relationship-oriented stance and argues that segregation protected Black people from mean White people, while Jake's reasoning considers the imbalance of numbers-there are more White barbers than Black barbers. Rather than asserting her point of view, Mallory sticks to questions and clarifications, prompting her students to say more. Then she brings it a step further toward collective action when she says, "This wasn't a problem that they could solve on their own, was it?"

This vignette is an inspiring illustration of a teacher working skillfully at the edge of students' social and moral development (and her own). She helped them to articulate their own perspective and also to reach toward the perspectives of others. She encouraged them to imagine collective responsibility by reminding them of a previous reading about Ruby Bridges. At this juncture, collaborative action research is aimed toward articulating these successes and reinforcing the skills in practice, sharing good ideas with others, and, simultaneously, scaffolding learning at the next level. In this classroom lesson, for example, Jacob uses the term, "colored." There is an opportunity to teach students about the charged and dynamic nature of language-how racism plays a role in shaping language and how language changes over time. Classroom interactions like these are effective teaching tools to bring teachers into conversation with each other, to give them an opportunity to pause and take in the significance of these student interactions, and to notice their own development.

\section{END-OF-YEAR: BECOMING “LITTLE KIDS WITH BIG WORDS” Cultural Identity Awareness}

Language development aids in the cognition of self as an autonomous being and as a social being. Vygotsky (1978) described how culture, language and identity development are linked: "An interpersonal process is transformed into an intrapersonal one," he wrote. "Every function in the child's cultural development appears twice: first, on the social level, 
and later, on the individual level; first, between people...and then inside the child" (p. 57). As students read stories of immigration, war, and the Civil Rights movement, classroom conversations expanded to include students' stories of family immigration, military deployment, and courage in confronting injustice. They began to question their own identities and cultures. Elizabeth journaled about a touching interaction with one of her fourth graders:

I had one student come up to me after we read The Candy Shop (Wahl, 2005), and asked how she could describe her culture. I was taken aback by this comment. Describing other cultures in other countries seems so much easier. We talked about what her family believed in and what they thought about work and school and we decided that was her culture. It was an incredible conversation.

\section{Empowering Students to Become "Little Kids with Big Words"}

At the beginning of the year, teachers were concerned that their students, many of them from poor and low-income families, would not be able to keep up with the rigorous vocabulary demands of the new curriculum. However, by year's end, Elizabeth noted, "As my students have worked on increasing their vocabulary, I feel like they have been empowered. Some of them are hungry for new, big words and love being able to have the right word." Across all grades, teachers described the sense of empowerment that comes with learning "big" words. On completing Because of Winn Dixie, Kathy told her thirdgrade students they were going to talk about "love." Her pride in her students is evident in her journal reflection:

I looked around and waited for red faces to appear and a giggle...but there was nothing. One student who rarely has a voice said, "Love is having confidence that you can trust someone." I couldn't believe my ears! I said to them I couldn't believe the big words they were using for such little people. One of my students said, "Yes, we have become little kids with big words."

Students spoke about their own struggles and asked perceptive questions about race, culture, love, loss, and responsibility and teachers revised their thinking about what their students could handle. And, as students demonstrated their enthusiasm for being "little kids with big words," teachers' confidence in their students' abilities became stronger. We also noticed that becoming "little kids with big words," also meant becoming "little kids with big thoughts and big actions." Many students now came to school eager to share their thoughts on current events, such as immigration and religious diversity. Teachers reported that students were more likely to speak up to intervene in bullying and to support a classmate that was struggling. They seemed to become even fonder of their students, and they leaned into both the discomfort and joy of their work with renewed energy and hope. 


\section{DISCUSSION}

\section{A Developmental, Reciprocal Process}

Practical concerns about time and space were paramount at first but, over time, teachers began to voice their concerns differently; they began to focus on their own skill development rather than on logistical constraints, their students' lack of exposure, or the community's lack of readiness for a curriculum that dealt openly with social injustice; as practical issues were addressed, teachers' concerns focused on their own skill development and re-conceptualizing their classroom role. By articulating their questions and then having opportunities to study their practice through reflective journaling and debrief sessions, teachers became more confident about confronting pedagogical challenges in the classroom. This self-reflective stance took us into new terrain in the realm of individual introspection and collective sharing.

As students engaged with the issues that the characters in the books encountered, they found common ground, regardless of racial and cultural differences. Mallory said, "They are comfortable with the cultural differences; it was a bigger deal for the teachers than for the students. They had not thought about racism but now they are noticing injustices more and they bring it up and point it out in class." Another teacher reflected, "Students are sometimes proving us wrong. They do get it. They are more aware of and care more about social issues than we thought." As they engaged in the hard work of pedagogical change, teachers' abilities to make adjustments in classroom practice were animated by becoming more proximal to their own concerns and to the concerns of their students.

Furthermore, as I witnessed the work of teachers and heard their reflections, I became aware of my own developmental process as I tried to enact my role in a new way. I had to learn how to listen intently for subtle experiential knowledge, how to facilitate deep and meaningful collaboration among teachers, how to be aware of my own assumptions, and how to hold a space open for questioning, complexity, and uncertainty.

\section{You Have to Learn Your Students}

SEL curriculum implementation is a developmental and interpersonal process for students and teachers involving a risky re-organization of classroom relationships. A year after the conclusion of this project, I returned to ask teachers: What were the most important pieces of learning now that they had two years of working with the curriculum? Third grade teacher, Kathy, said, "You have to learn your students. Know where your students are coming from-the conditions of their lives...what you know about them you can integrate in the class so that you can speak to the issue they are dealing with."

Kathy's words, "you have to learn your students," beautifully conveys an interpersonal, developmental process that is both cognitive and emotional. What had initially been uncertain terrain-how to safely open the door for students to talk about their lives-had now become a source of information for better teaching. Her statement also pointedly positions the teacher as the learner and the student as the teacher. To "learn your students" is a literacy skill and thoughtful, well-facilitated action research can help teachers learn to read and comprehend their students. Notably, I learned that it is equally important 
for university-based partners to "learn the teachers." This requires an ability to be vigilantly attentive to teachers' observations and assertions, to probe for the subtle knowledge they have about their work, to understand what is at stake in classroom interactions, and to honor the subterranean relational and emotional landscape of their practice. As the university partner in this process, intellectual humility involved a willingness to constrain my desire to have others know what I know, in order to be attentive and open to learning what teachers and students know.

\section{Zone of Collaborative Development}

Balakrishnan and Claiborne (2012) conducted participatory action research on the implementation of moral education in city, town and rural schools in Malaysia. They examined group conversations among students and they demonstrated the cultural and social embeddedness of moral reasoning. They posited that the individualistic construct of Vygotsky's $(1978,1986)$ "zone of proximal development" (ZPD) is complemented by a collective process in which there can be movement toward a "zone of collaborative development," (ZCD) which animates development in both the individual and the collective. At the beginning of the school year, teachers addressed their comments to me rather than to each other, but as the year progressed, they began to take steps toward collaborating with each other - sharing ideas and posing dilemmas in a way that approached a more "ideal" professional learning community (Clausen et al., 2009); however, sustained, robust collaboration would require consistent efforts to prioritize collaboration over a longer period of time.

The trajectory of change, from logistical worries, to concerns about students' abilities, to an introspective self-assessment and exploration, is supported by both collective commitment and by carefully tending to each level of concern while, simultaneously, working to move toward the next level of discomfort. Facilitating dialogic action research within the "zone of collaborative development" is an elusive and worthy goal that requires time, skill, and multi-level investment. These conditions are hard to meet.

\section{Long-term Results}

The implementation process involved consensus and commitment from administrators, who had to work out logistical issues like space and time; teachers, who had to learn the new curriculum and implement the various components with fidelity; and students, who had to adjust to new pedagogies and expectations. The curriculum was implemented in variable ways across the school, and more effectively in the classrooms of teachers that participated in the action research project. At the end of the first school year, Elizabeth wrote, "I am anxious to see how this will make a difference. Will they begin to live what they say? Will reading scores change?" After four years of not making Annual Yearly Progress, Hillside Central School students accomplished that evasive benchmark a year after this curriculum was implemented. The school continued to meet these high standards for four years; however, over time, several changes have contributed to diminishing results: several teachers who were part of this project left the school and new teachers did not have the professional development opportunity described in this article; new 
curriculum demands made it difficult to sustain fidelity to complex and demanding socialemotional learning; there have been several changes in state-wide reading assessments.

When I recently followed up, I learned that there is wide variability in how SEL is being implemented. New teachers have the same concerns as those discussed in this article; facilitating classroom conversations about racial and cultural diversity in a school that is 98\% White, and managing the emotions that arise when discussing sensitive topics, requires training that most teachers so not have. Reading scores have declined again and, although there is no way to know for certain, it appears that the lack of on-going professional development support for teachers may have played a role in that decline.

\section{RECOMMENDATIONS AND NEXT STEPS}

The lessons learned from this action research project-collaborating with intellectual humility, utilizing the knowledge of teachers, honoring the developmental process, and being aware of reciprocal learning-constitute an ethic of practice for university-school action research partnerships. As I reflect on this experience, I believe there are several action research steps that would make a project like this stronger.

- Students are astute observers of their social and emotional milieu. Including student action research during curriculum implementation process would provide valuable perspectives on teaching and learning (see Cammarota \& Fine, 2008).

- Hillside Central School is located in an under-resourced, low-income community. Historically, Hillside students have felt social exclusion when they go to middle school due to class differences and they are much less likely to complete high school and go to college (San Antonio, 2004). The SEL curriculum and action research might have been a powerful way for teachers and students to identify and address the unjust conditions of their own lives (see Nucci, 2016); however, this theme was not engaged.

- Finally, although the project was 7-months long, there was no plan for on-going professional development. The successes of projects like this one will be lost unless there is an investment in training newly hired teachers and administrators. A helpful strategy would be to have experienced and effective teachers, who are confident using the SEL curriculum, become mentors to teachers who are new to the school. Ideally, teacher-to-teacher mentoring and professional development would be compensated.

\section{CONCLUSION}

Teachers began a conversation with their students and with each other that led to new ways of thinking about their practice, classroom interactions, and their students' abilities. Likewise, we all learned new ways of being present and mindful of learning as a progressive, relational process that makes it possible and desirable to be deeply and 
courageously introspective about the experiences and values that shape us and what we bring to our practice. Recognizing action research as a developmental and inter-subjective experience, we can hold an ethic of practice that calls forth multiple representations of experience, privileges complexity, sustains curiosity, is embedded within a socio-cultural context, and aims toward the collaborative, process-oriented construction of knowledge. However, these shifts are not self-sustaining; they require on-going investment in action research and professional development.

\section{ACKNOWLEDGEMENTS}

The author would like to thank the teachers and Principal of Hillside Central School, Professor Robert L. Selman, and Harvard University graduate students, Trisha Ross Anderson, Elana Snow, Christopher San Antonio, and Tracy Taylor.

\section{REFERENCES}

Balakrishnan, V. \& Claiborne, L. B. (2012). Vygotsky from ZPD to ZCD in moral education: Reshaping Western theory and practices in local context. Journal of Moral Education, 41(2), 225-243.

Bandura, A. (1977). Social learning theory. Oxford, England: Prentice Hall.

Boyatzis, R. E. (1998). Transforming qualitative information: Thematic analysis and code development. Thousand Oaks, CA: SAGE.

Boyd, C. D. (2011). Charlie Pippin. New York, NY: Simon \& Schuster Publisher.

Bradbury-Huang, H. (2010). What is good action research? Why the resurgent interest? Action Research, 8(1), 93-109. https://doi.org/10.1177/1476750310362435

Brighton, C. M. (2009). Embarking on action research. Educational Leadership, 66(5), 40-44.

Cammarota, J., \& Fine, M. (Eds.). (2008). Revolutionizing education: Youth participatory action research in motion. New York, NY: Routledge.

Choudhury, S. (2015). Deep diversity: Overcoming us vs. them. Toronto, ON: Between the Lines.

Clausen, K. W., Aquino, A-M., \& Wideman, R. (2009). Bridging the real and ideal: A comparison between learning community characteristics and a school-based study. Teaching and Teacher Education, 25, 444-452.

Cochran-Smith, M., \& Lytle, S. L. (2001). Beyond certainty: Taking an inquiry stance on practice. In A. Lieberman \& L. Miller (Eds.), Teachers caught in the action: Professional development that matters. New York, NY: Teachers College Press. 
Cohen, J. (2006). Social, emotional, ethical, and academic education: Creating a climate for learning, participation in democracy, and well-being. Harvard Educational Review, 76(2), 201-237.

Collaborative for Collaborative, Academic, and Social-Emotional Learning (CASEL). (2018). Retrieved from August 4, 2018 https://casel.org/what-is-sel/approaches/

Conoley, J. C., \& Conoley, C. W. (2010). Why does collaboration work? Linking positive psychology and collaboration. Journal of Educational and Psychological Consultation, 20(1), 75-82.

Curtis, C. P. (2002). Bud, Not Buddy. New York, NY: Random House.

Darling-Hammond, L. (1996). The quiet revolution: Rethinking teacher development. Educational Leadership, 53(6), 4-10.

DiCamillo, K. (2009). Because of Winn-Dixie. Somerville, MA: Candlewick Press.

Durlak, J. A., Weissberg, R. P., Dymnicki, A. B., Taylor, R. D., \& Schellinger, K. B. (2011). The impact of enhancing students' social and emotional learning: A meta-analysis of school-based universal interventions. Child Development, 82(1), 405-432.

Elias, M. J. (2006). The connection between academic and social-emotional learning. In M. J. Elias \& H. Arnold (Eds.), The educator's guide to emotional intelligence and academic achievement. Thousand Oaks, CA: Corwin Press.

Elias, M. J., O’Brien, M. U., \& Weissberg, R. P. (December 2006). Transformative leadership for social-emotional learning. Student Services, National Association of School Psychologists. Retrieved November 2, 2018 from http://citeseerx.ist.psu.edu/ viewdoc/download?doi=10.1.1.307.5352\&rep=rep1\&type=pdf

Elizabeth, T., Ross T. A, Snow, E., \& Selman, R.L. (2012). Academic discussions: An analysis of instructional discourse and an argument for an integrative assessment framework. American Educational Research Journal, 49(6), 1214-1250.

Fine, M. (2018). Just research in contentious times: Widening the methodological imagination. New York, NY: Teachers College Press.

Friend, M., \& Cook, L. (2007). Interactions: Collaboration skills for school professionals, $5^{\text {th }}$ ed. Boston, MA: Pearson Education, Inc.

Gilligan, C. (1982/2016). In a different voice: Psychological theory and women's development. Cambridge, MA: Harvard University Press. 
Goddard, Y. L., Goddard, R. D., \& Tschannen-Moran, M. (2007). A theoretical and empirical investigation of teacher collaboration for school improvement and student achievement in public elementary schools. Teachers College Record, 109(4), 877896.

Grierson, A. L., \& Woloshyn, V. E. (2005). Transforming literacy assessment practices through an action research professional learning community. Ontario Action Researcher, 8(2), article 2.

Hill, P. C., \& Sandage, S. J. (2016). The promising but challenging case of humility as a positive psychology virtue. Journal of Moral Education, 45(2), 132-146.

Hoffman, D. M. (2009). Reflecting on social and emotional learning: A critical perspective on trends in the United States. Review of Educational Research, 79(2), 533-556.

Johnson, J. (Fall 2001). Principles of effective change: Curriculum revision that works. The Journal of Research for Educational Leaders, Vol. 1(1). Retrieved August 1, 2018 from http://www2.education.uiowa.edu/archives/irel/fall01/Johnson 0101.htm

Kemmis, S. (2009). Action research as a practice-based practice. Educational Action Research, 17(3), 463-474. doi: 10.1080/09650790903093284

Kohlberg, L. (1976). Moral stages and moralization: The cognitive developmental approach. In T. Lickona (Ed.), Moral development and behavior: Theory, research, and social issues. Holt, NY: Rinehart and Winston.

Kohlberg, L. (1981). Essays on moral development, Vol. I: The philosophy of moral development. San Francisco, CA: Harper \& Row.

Kress, J. S., \& Elias, M. J. (2006). Building learning communities through social and emotional learning: Navigating the rough seas of implementation. Professional School Counseling, 10(1), 102-107.

Kreuger, E. (2005). Teacher research as a mode of delivery for professional development. Ontario Action Researcher, 8(1), article 3.

Kroeger, S., Beirne, J., Kraus, T. (2015). You make the road by walking: A case study of partnership and collaboration. Action Research, 13(4), 354-371. doi:10.1177/1476750314568206.

Lewin, K. (1947). Frontiers in group dynamics: Concept, method and reality in social science, social equilibria and social change. Human Relations, 1(5). 
Meyers, A. B., Tobin, R. M., Huber, B. J., Conway, D. E., \& Shelvin, K. H. (2015). Interdisciplinary collaboration supporting social-emotional learning in rural school systems. Journal of Educational and Psychological Consultation, 25(2/3), 109-128.

Mitchell, M. K. (1998). Uncle Jeb’s barbershop. New York, NY: Simon \& Schuster.

Nakkula, M. J., \& Ravitch, S. M. (1997). Matters of interpretation: Reciprocal transformation in therapeutic and developmental relationships with youth. San Francisco, CA: Jossey-Bass.

Ng-A-Fook, N., Radford, L., Yazdanian, S., \& Norris, T. (2013). Empowering marginalized youth: Curriculum, media studies, and character development. Canadian Journal of Action Research, 14(1), 38-50.

Nucci, L. (2016). Recovering the role of reasoning in moral education to address inequality and social justice. Journal of Moral Education, 45(3), 291-307.

Nucci, L., Creane, M. W., Powers, D. W. (2015). Integrating moral and social development within middle school social studies: A social cognitive domain approach. Journal of Moral Education, 44(4), 480-497.

Peterson, S. S., Swartz, L., Bodnar, S., McCaigg, G., Ritchie, S., Dawson, R., \& Glassford, J. (2010). Collaborative action research supporting teachers' professional development as exemplified by one teacher team's action research on a study of silent reading. Ontario Action Researcher, 11(1), article 3.

Sagor, R. (2000). Guiding school improvement with action research. Alexandria, VA: Association for Supervision and Curriculum Development.

San Antonio, D. M. (2004). Adolescent lives in transition: How social class influences the adjustment to middle school. Albany, NY: State University of New York Press.

Selman, R. L. (2003). The promotion of social awareness: Powerful lessons from the partnership of developmental theory and classroom practice. New York, NY: Russell Sage.

Smith, B. H., \& Low, S. (2013). The role of social and emotional learning in bullying prevention efforts. Theory into Practice, 52(4), 280-287.

Tieken, M. C. (2014). Why rural schools matter. Chapel Hill, NC: University of North Carolina Press. 
Truscott, S. D., Kearney, M. A., Davis, D. E., Roach, A. T. (2016). Intellectual humility and morality as consultee-centered consultation epistemologies. Journal of Educational and Psychological Consultation, 27(1), 1-17.

Turner, A. N. (September 1982). Consulting is more than giving advice. Harvard Business Review. Retrieved from https://hbr.org/1982/09/consulting-is-more-than-givingadvice.

Villegas-Reimers, E. (2003). Teacher professional development: An international review of the literature. Paris, France: International Institute for Education Planning.

Vygotsky, L. S. (1978). Interaction between learning and development. In M. Cole, V. JohnSteiner, S. Scribner, \& E. Souberman (Eds.), Mind in society: The development of higher psychological processes. Cambridge, MA: Harvard University Press.

Vygotsky, L. S. (1986). Thought and language. Cambridge, MA: MIT Press.

Wahl, J. (2005). The candy shop. Watertown, MA: Charlesbridge.

Zins, J. E., Weissberg, R. P., Wang, M. C., \& Walberg, H. J. (2004). Building academic success on social and emotional learning: What does the research say? New York, NY: Teacher's College Press.

\section{BIOGRAPHICAL NOTE:}

Dr. Donna Marie San Antonio is an Associate Professor of Counseling and Psychology at Lesley University. For twenty-five years, she directed the Appalachian Mountain Teen Project, an activity-based counseling program that she founded in 1984 to serve lowincome and struggling youth in central and northern NH. Dr. San Antonio is a frequent consultant to rural school and community programs addressing social, emotional, and economic barriers to success for children and youth. She is a licensed School Counselor and School Psychologist. Research and writing interests include developmental transitions for adolescents and emerging adults; rural education; social class and life course decisionmaking; experiential education; adventure therapy; school-based mentoring; school climate and social-emotional development; cross-role and cross-institutional collaboration; cross-cultural ethnographic research; and community and school-based participatory action research for social change. Dr. San Antonio serves on the Editorial Board of Journal of Experiential Education and is a Founding Member of International Society of Policy, Research and Evaluation in School Counseling. She is the Coordinator of UNESCO-UNITWIN Project on Lifelong Career Counseling for the Graduate School of Arts and Social Sciences. 